\title{
A MEDIAÇÃO TRANSFORMATIVA COMO INSTRUMENTO DE EMPODERAMENTO DAS MULHERES NA AGENDA AMBIENTAL DE DESENVOLVIMENTO SUSTENTÁVEL: ENSAIO SOBRE A PACIFICAÇÃO DE CONFLITOS INTERGERACIONAIS
}

Adriana Machado Yaghsisian

Doutoranda em Direito Ambiental Internacional pela Universidade Católica de Santos. Integra o grupo de pesquisa em Energia e Meio Ambiente, da Pós-graduação Mestrado e Doutorado da Unisantos. Conciliadora e Mediadora pela EPM/ SP, com atividade no anexo do Juizado Especial Cível da Unisantos. Atualmente é professora do curso de Direito da Universidade Católica de Santos e instrutora do Curso de Extensão, de Capacitação de Conciliadores e Mediadores da Unisantos certificada pelo TJ/SP.

Gilberto Passos de Freitas

Doutor em Direito pela Pontifícia Universidade Católica de São Paulo (2003). É desembargador aposentado do Tribunal de Justiça do Estado de São Paulo, Supervisor do Grupo de Mediação e Resolução de Conflitos Socioambientais e Urbanísticos, no CEJUSC Central, do TJSP, Membro Consultor da Comissão Nacional do Direito Ambiental, do Conselho Federal da OAB e professor do programa de pós-graduação mestrado e doutorado da Universidade Católica de Santos.

\section{Resumo}

O enfrentamento da mudança do clima e de outros desafios hodiernos demandam a adoção de soluções pacificadoras para resolução de conflitos socioambientais na perspectiva do desenvolvimento sustentável intergeracional. Essa arquitetura aponta para a participação plena das mulheres, como condutoras de processos marcados pela transformação de comportamentos socioambientais, que encontra espaço fértil na mediaçáo transformativa, enxergada como prática que implica a revalorização e o reconhecimento mútuo dos envolvidos. Nesse contexto, o trabalho abordará noçóes importantes acerca da mediação e do empoderamento das mulheres sob o viés da relação entre gênero, meio ambiente e desenvolvimento sustentável, como estratégia para a pacificaçáo de conflitos intergeracionais e de incremento da participação e engajamento das mulheres nos processos de paz dos conflitos socioambientais, em sintonia com os objetivos preconizados pela ONU Mulheres, criada em 2010, e a Agenda 21. 


\section{Palavras-chave}

Mediação transformativa socioambiental; Empoderamento das mulheres; Desenvolvimento sustentável intergeracional.

\section{Abstract}

Facing climate changes and other challenges of today's world requires the adoption of peacemaking solutions to solve social-environmental conflicts in the perspective of intergenerational sustainable development. This architecture points to the total participation of women, as conductors of the processes marked by the transformation of social-environmental behaviors, which finds fertile ground in transformative mediation, seen as a practice that implies revaluation and mutual recognition of the parties involved. Under this context, the work will deal with important notions on mediation and women's empowerment according to the relationship between genre, environment and sustainable development as a strategy of pacifying intergenerational conflicts and increasing women's participation and engagement in the peacemaking processes of social-environmental conflicts, complying with the goals recommended by UN Women, created in 2010, and Agenda 21.

\section{Key words}

Social-environmental Transformative Mediation; Women's Empowerment; Intergenerational Sustainable Development.

\section{Introdução}

O presente artigo apresenta necessidade de empoderamento das mulheres como estratégia para pacificar os conflitos socioambientais e alcance do desenvolvimento sustentável intergeracional, sob o viés da mediação transformativa.

A desigualdade de gêneros afeta o desenvolvimento sustentável, posto que repercute diretamente na permanência da pobreza e, por conseguinte, no incremento dos conflitos socioambientais. As mulheres são mais afetadas do que os homens em razão de seu "status" desigual na sociedade, proibiçóes de igualdade de Direitos e oportunidades, falta de acesso a serviços, além da exclusão no processo de tomada de decisóes que afetam suas vidas e desenvolvimento.

Para o alcance do desenvolvimento sustentável é necessário oferecer a igualdade de direitos e de necessidade entre homens e mulheres.

Ao lado desse cenário, o sentimento de insatisfação pública é uma constante ante a atuação do Poder Público, o que se estende, também, à prestação jurisdicional. Mais 
especificamente, o Poder Judiciário está sobrecarregado, além de se mostrar ineficiente devido à morosidade e à desatualização da legislação a ser aplicada.

Nesse contexto, a mediação transformativa é estratégia hábil a construir o empoderamento das mulheres na direção do desenvolvimento sustentável, inserindo-as como atrizes de políticas públicas, programas e tomada de decisóes, de modo a facilitar a aproximação das partes desenvolvidas. Assim, elas encontrarão, certamente, um resultado satisfatório, de maneira consensual, (re)construído ao longo do processo de mediação.

A metodologia empregada no presente trabalho consiste no método de abordagem dialético, posto que estruturada no dinamismo e mudança das relaçóes, além do sistêmico, que enxerga a sociedade e suas partes como um fenômeno organizacional, como um sistema que apresenta um mecanismo próprio e dinâmico de equilíbrio, e, também, hermenêutico, alicerçado que está na certeza de que o contexto é o eixo sobre o qual se explica toda e qualquer comunicação humana.

Nessa linha, o presente trabalho examinou, primeiramente, a existência de conflitos, além do conceito de mediação e suas implicaçóes na gestáo ambiental, perspassando para a abordagem do empoderamento da mulher na perspectiva do desenvolvimento sustentável. Por fim, aborda-se a sua inserção na agenda internacional e nos compromissos internacionais.

\section{0 Conflito}

A compreensão superficial do conflito que está sendo vivenciado está relacionada, muitas vezes, a sua má-administração, posto que se procura solucionar apenas o que está aparente e, dessa forma, não se trabalha o verdadeiro conflito. Para um bom convívio social é necessário que se descubra a queixa real do conflito e como podemos solucioná-lo da maneira mais adequada (CARDOSO et al, 2014).

O conflito ocorre entre diferentes agentes, com posiçóes, argumentos, interesses, e desejos incompatíveis. É enxergado como um estado de tensão, em razão da existência de um confronto entre as partes envolvidas (TORRES, 2006).

Ao surgir o conflito há uma verdadeira disputa entre as partes, que enxergam a divergência de maneira negativa, o que, por sua vez, provoca a insegurança, o medo de terem de enfrentar o conflito sozinhas. As partes que estão envolvidas no conflito não conseguem enxergar que, através dele, enfrentam uma fase de possíveis transformações, ao contrário, o encaram como sendo uma crise que provoca apenas sentimentos de angústia e sofrimento (SALES, 2007, apud MOREIRA, 2013).

O conflito é um fator de evolução quando administrado e visualizado como parte da dinâmica natural humana, que implica na possibilidade de avaliação de capacidades 
e possibilidades, além de estimular o autoconhecimento e revitalizar normas (TORRES, 2006).

Os estudiosos, acerca do tema, dividem o conflito em duas categorias: conflito real, manifesto ou verdadeiro; e conflito falso ou aparente. É importante fazer sua distinção porque, se não for trabalhado o verdadeiro conflito, este não será de fato solucionado e as partes não sairão satisfeitas ao final do processo (MOREIRA, 2013).

O conflito real é aquele que demanda solução, é o que motivou a divergência entre as partes. É este que causa sentimento de mal-estar entre os sujeitos do conflito. Com frequência, surge como problema secundário, em razão da dificuldade de externá-lo, enquanto que o conflito falso desponta como se fosse o verdadeiro, embora assim não aconteça (CARDOSO et al, 2014).

O conflito falso ou aparente é aquele que tenta se apresentar como o verdadeiro problema, mas ele é apenas um dos efeitos do verdadeiro motivo do conflito, cuja resoluçáo é imprescindível para se evitar o seu agravamento.

\subsection{A Mediação como Meio de Enfrentamento do Conflito}

A mediação é um meio consensual estabelecido como forma de solucionar o conflito que, através da atuação de um terceiro imparcial facilitador, qual seja, o mediador, ajudará, por meio do diálogo, os mediados a encontrarem por si mesmos o caminho para a solução mais adequada. Importante dizer que, normalmente, esta técnica vem sendo aplicada extrajudicialmente e apresenta técnicas de aplicação embasadas em princípios próprios (MOREIRA, 2013).

Com forte influência nas Ordenações Filipinas, a Mediação, no Direito nacional, foi regulamentada por intermédio da Carta Constitucional do Império de 1824, como forma de conciliação, por intermédio de um Juiz de Paz. A reforma do Código de Processo Civil, em 1994, que previu a conciliação prévia, e a instauração dos Juizados Especiais (lei 9.099/95), que reconheceu a mediação como um importante mecanismo, foram preponderantes para o fomento a esse mecanismo pacífico de resolução de conflitos (BEDÊ, FERENC e RUIZ, 2008).

Alinhado a esse contexto, se encontra a Emenda Constitucional no 45/2004, que iniciou a implantação da Reforma do Judiciário, acrescentou ao rol de direitos fundamentais o direito à "razoável duração do processo e os meios que garantam a celeridade da sua tramitação" (inciso LXXVIII, acrescentado ao artigo $5^{\circ}$ da Constituição Federal pela mencionada Emenda), demonstrando a relevância que o constituinte atribui à celeridade na tramitação processual e servindo de fundamento para uma série de reformas ainda não implementadas (SOUZA, 2012, p. 43). 
A Emenda referenciada criou, também, o Conselho Nacional de Justiça, órgão que vem desempenhando papel fundamental na profissionalização da gestão no âmbito do Poder Judiciário, como, exemplificativamente, na edição da Resolução n. 125/10, que instituiu a Política Pública de Tratamento Adequado de Conflitos, por meio do uso da conciliação e mediação (CARDOSO et al, 2014).

A mediação é utilizada em diversos Estados, com ênfase nos Estados Unidos, em temas relacionados a divórcio, disputas havidas nas comunidades, e em relaçóes empresariais, laborais e internacionais (BUSH e FOLGER, 2010).

Constitui instituto valioso para o (re)estabelecimento dos laços sociais diante de uma realidade social marcada pelo tempo escasso e intolerância, de modo a construir pontes de diálogos entre os envolvidos, que valoriza conceitos como a colaboração, o diálogo, a democracia, a responsabilidade e a cidadania (SOARES, p. 67).

Adiante, se examinará a escola de mediação que mais se entrelaça como instrumento de empoderamento das mulheres na perspectiva do desenvolvimento sustentável intergeracional, no caso, a mediação transformativa, uma vez que fundada na revalorização e reconhecimento das pessoas, que atuam como pontes transformadoras da realidade socioambiental.

\subsubsection{A Escola da Mediação Transformativa}

A revalorização e reconhecimento mútuo dos envolvidos têm importância ímpar na mediação transformativa, segundo a teoria dos estudiosos Bush e Folger (2010), e este é o enfoque sugerido na obra "La Promessa de Mediación". Na obra "La Promessa de Mediación”, Bush e Folger ressaltam que o conflito deve ser enfrentado através de um novo enfoque, que se baseia no reconhecimento e na revalorização, ao contrário do que vem sendo praticado nos Estados Unidos, assim como em outros lugares.

De fato, será por intermédio da revalorização, no sentido de trazer autoconfiança, fortalecimento, estímulo e do reconhecimento, que os autores sustentam ser a mediaçáo um caminho não apenas possível para viabilizar acordos ou melhorar relaçóes humanas. Ela poderá ser hábil a transformar nossas vidas, pois inspirará tanto um sentido de maior vivacidade a respeito de sua própria capacidade pessoal (revalorização/ autodeterminação), como uma maior abertura e maior aceitação da pessoa colocada no lado oposto da mesa (reconhecimento) (CARDOSO et al, 2014).

A escolha entre um enfoque baseado apenas na satisfação ou na transformação estará marcada pela decisáo: ou continuamos sendo uma sociedade individualista ou seguimos para sermos uma sociedade diferente que sirva como referência para outras. A escolha do enfoque representa uma nova visão referencial de vida, que nos convida a novas possibilidades de consciência e de interaçóes humanas (BUSH e FOLGER, 2010). 


\subsubsection{A Importância do Mediador}

O mediador atua como um terceiro imparcial, de modo a facilitar o diálogo entre as partes a fim de se concretizarem os objetivos da mediaçáo, assim como deverá esclarecer que todo procedimento estará protegido pelo sigilo. É responsável por transformar o ambiente antes hostil em cooperativo e igualitário. É nesse sentido que o mediador transforma-se em pacificador social, sendo este um dos principais objetivos da mediação, que, transportada ao presente trabalho, encontra na figura da mulher a protagonista dessa atividade.

O fomento à prática do bom diálogo, condutor das partes à busca de resultados satisfatórios, ao lado da ênfase à existência de ganhos mútuos, constitui, outrossim, atividade ímpar do mediador.

$\mathrm{Na}$ corrente transformativa, o papel do mediador é provocar, estimular, ajudar as partes a se olharem, se reconhecerem. A sua tarefa consiste em ajudar as pessoas à "sentir o sentimento", olhando a si mesmas e não o conflito. O mediador auxilia as partes a procurarem um acordo interiorizado, que tenha como base uma negociação transformativa, e não só um acordo de palavras (WARAT apud TORRES, 2001).

Independentemente da técnica adotada, o mediador sempre terá que desenvolver a mediação dentro de limites legais, éticos e principiológicos, de sorte a assegurar a formação de um vínculo, sem exclusão de qualquer das partes, o estímulo ao protagonismo, e facilitação do reconhecimento do co-protagonismo (SOARES, 2008).

\subsubsection{Papel da Mediação na Constituição Federal de 1988}

A utilização dos meios alternativos de resolução pacífica de conflitos, no caso, a mediação, encontra-se estruturada no preâmbulo da Constituição Federal de 1988, ao prever o comprometimento pela nossa sociedade, na ordem interna e internacional, com a solução pacífica das controvérsias.

Ao instituirmos o Estado de Direito, o destinamos a assegurar, entre outros, o bem -estar, concebido como o estado de paz que não existe quando há conflito, como valores supremos de uma sociedade.

Enxergados como direitos de terceira dimensão, no título dos princípios fundamentais, encontramos, no que respeita às relaçóes internacionais, a defesa da paz, secundada da solução pacífica de conflitos (artigo 4º, incisos VI e VII) (SARLET, 2009).

Afirma-se, com esse tratamento conferido pelo legislador, o compromisso com a solução pacífica das controvérsias, donde se extrai a adequação da mediação à Constituição Federal de 1988, sem qualquer ofensa aos seus dispositivos. 
Os direitos e garantias constitucionais constantes no artigo $5^{\circ}$ da Constituição Federal de 1988 têm aplicação a todo sistema processual, seja a autocomposição como heterocomposição (TORRES, 2006). Outrossim, a mediação não gera ofensa alguma aos direitos fundamentais da Constituição Federal de 1988.

Com efeito, o artigo $5^{\circ}$, inciso LIII, da Constituição Federal, estabelece a regra de que ninguém será processado nem sentenciado senáo pela autoridade competente. $\mathrm{O}$ mediador, na mediação, nada julga, mas atua como auxiliar das partes na busca de consenso.

O devido processo legal (artigo 5º, inciso LIV, CF), por igual, não é afastado, uma vez que a mediação implica opção pela utilização ou não a um procedimento previamente estabelecido, segundo a vontade das partes envolvidas que, não alcançando a composição pretendida, terão direito ao acesso ao Judiciário. Nesse contexto, também se alinham a garantia do contraditório e da ampla defesa, além da participação do advogado (artigo $133 \mathrm{CF})$.

O mediador não é julgador. A ele se atribui a tarefa de se (re) estabelecer a paz. E às partes a possibilidade de dialogar para a construção de um resultado satisfatório, sem implicar exame de matéria jurisdicional, com preservação da prestação jurisdicional, portanto (TORRES, 2006).

Frise-se, nesse contexto, a importância da Emenda Constitucional no 45/04, que iniciou a implantação da reforma do judiciário, ao acrescentar no rol de direitos fundamentais o direito à razoável duração do processo e os meios que garantam a celeridade da sua tramitação (inciso LXXVIII, artigo $5^{\circ} \mathrm{CF}$ ).

\section{0 Conflito Ambiental e sua Gestão}

A Política Nacional do Meio Ambiente, Lei no. 6.938/81, traz objetivos, diretrizes e princípios a serem seguidos no que diz respeito ao uso, controle, proteção e conservação do meio ambiente.

A referida Política também prevê medidas a serem tomadas pelo Poder Público, que visem à preservação, melhoria e recuperação do meio ambiente, assim como o equilíbrio do sistema ecológico. São por intermédio desses instrumentos protetores que a gestão ambiental se sustenta, além de instrumentos jurídicos como a ação popular, ação civil pública e ação penal pública, todos tendo em vista a proteção ambiental (TORRES, 2006).

$\mathrm{O}$ artigo $3^{\circ}$, inciso I, da Lei ${ }^{\circ}$ 6.938/81, estabelece o conceito legal de meio ambiente como "o conjunto de condiçóes, leis, influências e interaçôes de ordem física, química e biológica, que permite, abriga e rege a vida em todas as suas formas".

O meio ambiente é considerado direito de terceira geração, ou seja, faz parte daqueles direitos metaindividuais, coletivos e difusos, consubstanciados na solidariedade. 
Estudiosos acerca do tema entendem que esse direito está relacionado com o conceito de meio ambiente ecologicamente equilibrado e tem como característica ser um direito de titularidade coletiva ou seja, de proteção de toda coletividade (FERREIRA, 2010).

As necessidades humanas são ilimitadas, porém os recursos naturais não o são. $\mathrm{O}$ exaurimento desses recursos levaria a humanidade à crise, o que conduziria, por sua vez, à paralisação do processo econômico, que consiste na gestão desses recursos, limitados, que estão à disposição do homem. Até mesmos os bens renováveis, se utilizados sem qualquer racionalização, poderão não mais apresentar capacidade de autorregeneração (CARDOSO et al, 2014).

Nesse contexto, a gestão ambiental ganha destaque. Ela é a resposta para uma atuação empresarial responsável, onde, para proteger o meio ambiente, não é necessário pararmos de nos desenvolver economicamente, através da exploração desses recursos naturais (OLIVEIRA FILHO, 2004).

Essa nova percepção de desenvolvimento necessita do entendimento de que o homem pode utilizar os recursos do meio ambiente, mas desde que o faça de maneira sustentável, a fim de se proteger a dinâmica dos sistemas naturais. Apenas agindo de maneira racional, com a implementação de uma boa gestão ambiental, será possível viabilizar uma boa qualidade de vida às futuras geraçôes. Este conceito, de meio ambiente sustentável, tem destaque internacional, sendo adotado pela Comissão Mundial sobre o Meio Ambiente e Desenvolvimento, em que enfatiza ser este o caminho para satisfazer as necessidades humanas atuais, sem que prejudique as necessidades das futuras geraçóes (FERREIRA, 2010).

A Política Nacional do Meio Ambiente, embora não traga de modo explícito a utilização da mediação nos conflitos socioambientais, elenca alguns instrumentos formulados com base nos princípios que orientam o Direito Ambiental. Nessa linha, os princípios da participação e, consequentemente, os da informação e cooperação ganham realce na mediação na resolução de conflitos socioambientais (TORRES, 2006).

Os acordos internacionais dos quais o Brasil é signatário cuidam da participação pública, a saber, Agenda 21, Declaração do Rio, Convenção da Bio Diversidade e o Protocolo de Kioto.

O princípio 10 da Declaração do Rio de Janeiro aponta para a necessidade de proporcionar à sociedade mecanismos judiciais e administrativos, o que nos permite estendê-los aos extrajudiciais na perspectiva da resolução de questóes ambientais (TORRES, 2006).

Os conflitos ambientais podem ser conceituados como a disputa social, que ocorre quando alguém tem determinada pretensão em fazer uso de certo recurso natural e o outro cria uma barreira, de modo a impedir ou de regulamentar essa conduta. Eles podem 
ser divididos em dois tipos: a) conflitos de uso, no qual ocorre a disputa entre particulares, ou de particulares com o Poder Público, que têm intuito de fazer uso de certo bem ou recurso do meio ambiente; b) conflitos entre empreendedores, tanto públicos ou privados, que têm como objetivo a exploração dos recursos ambientais com a comunidade, que, por sua vez, visa à preservação ou sua conservação (ERNANDORENA, 2012).

O Brasil, em particular, tem sofrido com disputas relacionadas ao uso, acesso e ao aproveitamento desses recursos naturais. Isso se dá devido a alguns fatores, tais como: "gestão dos recursos ambientais limitados, instituiçôes debilitadas, meios escassos, dinâmicas sociais e econômicas cada vez mais complexas, falta de diálogo" (SILVA et al, 2010, p. 667) entre as partes envolvidas nas disputas socioambientais.

Nessa perspectiva, o investimento em gestão ambiental, de forma a viabilizar a sustentabilidade do meio ambiente, contribuirá para uma vida digna, com qualidade de vida, assim como transformará as relaçóes de uso, acesso e de aproveitamento dos recursos naturais. Para tanto, é importante fazer uso de meios que consigam lidar com o fator tempo e que disponibilizem recursos necessários, a fim de solucionar os conflitos ambientais.

A mediação encontra terreno fértil para a referida resolução, mormente pela sua capacidade voltada à busca de soluçóes criativas, adequadas ao caso concreto, como doravante se examinará.

\subsection{Da Adequação da Mediação em Conflito Socioambiental}

A mediação ambiental já vem sendo largamente utilizada pelos Estados Unidos desde 1970. Apesar de esta técnica favorecer o diálogo e a transparência do procedimento, no Brasil, o uso de tal técnica é eventualmente afastado, em decorrência do princípio da indisponibilidade do meio ambiente, por tratar-se de bem difuso, de uso comum do povo (ERNANDORENA, 2012).

A controvérsia a respeito da pertinência da autocomposição em conflitos ambientais persiste, entre nós, mormente quando se trata de celebraçóes de ajustamentos de condutas, acordados entre órgãos do Estado e os agentes causadores de acidentes coletivos, a fim de minimizar o dano ambiental.

Mesmo ao nos depararmos com julgados que estabelecem ser possível a realização de concessôes sobre o direito material em disputa transindividual, há grande parcela da doutrina discordante, no sentido de somente vislumbrarem tal possibilidade de concessóes quando se tratar de condições de cumprimento de obrigações legais, isto é, de discussóes a respeito de aspectos acidentais que envolvem a questão principal de direito difuso, já que estão limitados diante de interesse público indisponível (SILVA JUNIOR, 2009). 
Para que se possa fazer uso de técnicas alternativas de resolução de conflitos, em matéria ambiental, em tema que verse sobre direito indisponível, deve existir um limite acerca do tema, a saber, deverá ser realizada a exigência de haver a devida manutenção do meio ambiente, de modo que ele próprio consiga iniciar o processo de autorregeneraçáo (CARDOSO et al, 2014).

A gestão ambiental dos recursos naturais entrelaça-se com temas socioambientais, posto que examina como o homem usa e se apropria de tais recursos, e, em contrapartida, como o Estado cria normas e administra a utilização e seu aproveitamento (SILVA et al, 2010).

Ao fazer uso da mediação, as partes terão alto grau de participação através da discussão ampliada acerca do conflito, o que acarretará maior capacidade para absorção de valores e princípios que nortearam na escolha da solução final. Certamente, isso auxiliará, no futuro, às partes solucionarem, por si só, disputas informais, ou até mesmo possibilitará que nem sequer se instaure tal disputa.

Simone Alves Cardoso (CARDOSO et al, 2014) realça que:

os interesses a serem defendidos durante o processo de mediação serão comuns a todos os envolvidos, até mesmo os das pessoas públicas, pois, uma vez ocorrido o dano ambiental, este afetará, consideravelmente, as características que deverão conter o acordo. Com efeito, este deve observar os interesses individuais de cada parte, e conter, também, determinadas características, tais como: que tenha durabilidade, seja eficaz, justo, estável e adaptável. Acordos que não observem o interesse público poderáo acarretar na escassez de recursos naturais, contribuindo para o surgimento de novas disputas, e, consequentemente, no desgaste das relaçôes entre as partes envolvidas.

Nesta perspectiva, a presença do Poder Público durante o processo da mediação engrandece-se, a fim de não permitir que se distorça princípios e normas cogentes integrantes do ordenamento jurídico, garantidoras de um desenvolvimento sustentável do meio ambiente.

O estímulo do Poder Público na solução de disputas por meios consensuais, principalmente na área da prevenção, servirá como meio para fazer com que as políticas públicas sejam melhor implantadas, assim como as legitimará e ajudará a prevenir futuras disputas, se bem utilizadas.

Alguns sustentam a criação de uma Câmara de Mediação Ambiental em conselhos de meio ambiente, em diferentes níveis, como o CONAMA, envolvendo todos os instrumentos da gestão ambiental e conflitos socioambientais cuja solução dependa do diálogo entre os vários atores envolvidos. No entanto, a referida figura merece melhor exame, posto que tais conselhos não compreendem toda a dimensão teórica e os princípios relativos à mediação (TORRES, 2006). 


\section{Do Empoderamento das Mulheres na Agenda Ambiental do Desenvolvi- mento Sustentável}

Os enfrentamentos da mudança do clima e de outros desafios demandam a participação plena das mulheres, bem como da sabedoria coletiva. As mulheres têm um papel essencial no desenvolvimento sustentável, sendo que este, por sua vez, pode melhorar de forma significativa suas vidas, por meio da redução da pobreza e da proteção contra a violência, além de outros impactos adversos na saúde e no ambiente.

O desenvolvimento sustentável intergeracional não pode ser alcançado sem igualdade de gênero. Como estabelece a Organização das Naçóes Unidas para a Agricultura e Alimentação (FAO), caso fosse proporcionado às mulheres igual acesso que os homens têm a fertilizantes, sementes e ferramentas, a produção agrícola nacional aumentaria em até $4 \%$ e o número de vítimas da fome seria reduzido em 100 ou 150 milhóes (ANRIQUEZ e BOJANIC, 2014).

Atualmente as mulheres são o produto mais subutilizado. De acordo com o Secretário-Geral da ONU, Ban-Ki moon (BRITO, 2014), as mulheres são as mais afetadas pela pobreza por estarem "na linha de frente" e um recurso para o empoderamento feminino é a educação. Como exemplo da vulnerabilidade das mulheres, pode-se citar o fato de mais de $85 \%$ dos dois milhóes de vítimas da fumaça produzida por fogóes tradicionais são mulheres e crianças.

Além disso, com maiores oportunidades na educação e capacitação, as mulheres teriam maior facilidade no acesso ao setor moderno da economia e ao desenvolvimento econômico, segundo o enfoque teórico denominado "Mulheres em desenvolvimento MED” (KABEER, 1998).

Sustentamos a tese de que a educação é materializada e implementada pela mediação transformativa, que vem a ser uma das ferramentas que transformará o comportamento das presentes e futuras geraçôes.

Segundo Michelle Bachelet, Diretora Executiva da Entidade das Naçóes Unidas para a Igualdade de Gênero e o Empoderamento das Mulheres (ONU Mulheres), em pronunciamento anterior à Conferência das Naçóes Unidas para o Desenvolvimento Sustentável $($ Rio + 20), e que tinha por fim que o documento final da Rio+20 contemplasse a participação plena das mulheres no desenvolvimento sustentável, as mulheres têm papel ímpar como promotoras e defensoras do desenvolvimento sustentável. Em suas palavras: "O mundo não pode mais se permitir a exclusão das mulheres. O desenvolvimento sustentável náo pode acontecer sem metade da populaçáo mundial".

Foi apenas nos anos 70 que se verificou certa preocupação com as condiçóes das necessidades básicas, a produtividade rural e as atividades no setor informal, na qual foi incluído o papel da mulher no contexto do desenvolvimento. 
Posteriormente, na década de 90, houve o surgimento da perspectiva de Gênero em Desenvolvimento (GED), que parte da premissa segundo a qual as mulheres têm sido excluídas do processo de desenvolvimento. Assim, passou-se a sustentar a necessidade de alcançar a igualdade legal, política e social das mulheres pela sua incorporação nas políticas públicas, que incidam nos interesses práticos e estratégicos femininos, a fim de melhorar sua posição na relação entre os gêneros e permitir seu empoderamento.

\subsection{Perspectivas Teóricas Acerca de Gênero, Meio Ambiente e Desenvolvimento Sustentável}

Para compreensão da relação entre gênero, meio ambiente e Desenvolvimento sustentável, formaram-se posturas teóricas a respeito, dentre as quais, as principais, são a perspectiva Ecofeminista; Mulheres e Meio Ambiente e Desenvolvimento (MAD) e Gênero, meio Ambiente e Desenvolvimento Sustentável (GMAD).

$\mathrm{Na}$ primeira perspectiva, tem-se o ecofeminismo, desenvolvido a partir das posturas de oposição dos movimentos ecologistas e feministas no final dos anos 70 e início dos anos 80 (HERNÁNDEZ, 2010) e em torno do qual surgem duas concepçóes, a saber, a oposição entre a esfera pública e privada, que remete ao lugar de formação de identidades, culturas éticas distintas entre os homens e mulheres, e a relação entre feminino e natural, que permitirá privilegiar o papel das mulheres na luta ecológica para contribuir na questão do meio ambiente (SORJ apud HERNÁNDEZ, 1992).

Por sua vez, duas vertentes surgem a partir desta perspectiva, que são o ecofeminismo cultural, que sugere existir uma relaçáo entre as mulheres com a natureza e foca a necessidade de se construir uma nova relação espiritual com ela, e o ecofeminismo social, que reconhece a complexidade da identidade humana, por meio da confluência e da inter-relação de vários eixos identitários, que correspondem objetivamente às diversas relaçóes sociais e que conduzem à conformação do tecido social no qual as pessoas estáo imersas (PLUNWOOD, 1993, apud MARTINEZ, 2003).

O ecofeminismo cultural é fortemente criticado porque considera que a mulher tem uma relaçáo superior com a natureza, determinada biologicamente, em certas situaçóes, o que, por seu turno, estaria apoiada em uma postura ecocentrista, que reconhece uma série de interesses de humanos e não humanos (TAVOLARO, 2001, apud HERNÁNDEZ, 2010). Nessa perspectiva, as mulheres, nas suas atividades cotidianas, estão mais próximas da natureza que os homens, no sentido espiritual e conceitual. Essa identidade seria reforçada pelos processos biológicos de reprodução. Haveria, então, determinismo biológico, que coloca a relaçáo das mulheres com a natureza em uma postura necessariamente conservacionista e geradora de vida. 
Segundo Hernández, as mulheres do terceiro mundo, especialmente as de escassos recursos, são as mais afetadas pela relação com a natureza, porque não têm poder aquisitivo para colocar suas demandas de bens e serviços proporcionados pelos sistemas modernos de produção, dado que existe uma desigualdade política e econômica na distribuição e acesso aos recursos.

Dentre várias construçóes teóricas existentes a partir desta concepção, ressalta-se, para o presente trabalho, a que enxerga a existência de vínculos entre a dominação e a opressão das mulheres e entre a dominação e exploração da natureza, embora fortemente criticado pela doutrina internacional ao argumento, dentre outros, de que se considera a dominação da mulher e da natureza quase exclusivamente fundamentada na ideologia, negligenciando as fontes materiais desta dominação, baseadas na vantagem econômica e no poder político.

O fato é que tanto as mulheres quanto à natureza são categorias socialmente construídas, o que lhes permite mudar no tempo e no espaço. Associar a ideia de que as mulheres têm um vínculo especial com a natureza impede a sua percepção, tanto quanto a dos homens das diferentes sociedades, de que podem olhar e experimentar as coisas de diversas formas, mormente levando-se em conta que as relaçóes das mulheres com a natureza variam segundo a classe, a raça, a etnia, a nacionalidade, a idade, dentre outros fatores. Além disso, a relação das mulheres com o meio ambiente deve transcender as conexôes simbólicas (AGARWAL, 1992 apud VAZQUEZ, 1999).

Em que pese a existência de críticas a essa corrente, não se pode negar as contribuiçóes para o estabelecimento da conexão entre a opressão da natureza com a opressão das mulheres, segundo Carmen Osório Hernández.

Desse modo, na perspectiva da construção de propostas alternativas para um desenvolvimento sustentável, uma das contribuiçóes consiste no reconhecimento do papel das mulheres na conservação da biodiversidade ao dar ênfase à cultura local, à valorização do conhecimento popular sobre o uso e manejo de recursos, além do estímulo à participação no resgate e aumento da biodiversidade. A biodiversidade, então, em consonância com o pensamento dos defensores da ecologia social, é enxergada não só como um conceito de origem biológico, mas também como o resultado de práticas milenares das comunidades tradicionais, afetas á seara cultural, que mantém e, em certos casos, acentua a diversidade local, como é o caso da participação das mulheres de comunidades rurais na produção de hortas e plantas medicinais (HERNÁNDEZ, 2010).

A segunda perspectiva, no caso Mulher e Meio Ambiente e Desenvolvimento (MAD): de Vitima à protetora dos problemas ambientais, surge na metade da década de 80 e tenciona incluir os interesses de mulheres e ambientalistas na tomada de decisóes e instrumentação de açóes. Nessa linha, a participação das mulheres, enquanto administradoras 
e usuárias dos recursos deveria integrar a arquitetura de políticas e programas de desenvolvimento sustentável.

A corrente referenciada está alinhada ao pensamento sobre "Mulheres em Desenvolvimento (MED)" e influenciada pela corrente ecofeminista, que se assenta na ideia de que as mulheres têm uma afinidade especial com a natureza, tendo como eixo central para análise a importância que as mulheres têm, em especial nos países subdesenvolvidos, no manejo dos recursos naturais, uma vez que, em razão das condiçôes de pobreza, são mais vulneráveis diante da escassez e degradação de recursos, além do vetusto papel que ostentam na produção para a autossubsistência no contexto rural.

Além disso, a referida corrente identifica, nas mulheres, sob o prisma de uma categoria homogênea, habilidades e conhecimentos especiais que lhes permitem desenvolver projetos de conservação, como estratégias para o desenvolvimento sustentável,na agenda ambiental de desenvolvimento sustentável, encontrando aí, a mediação transformativa, terreno fértil enquanto instrumento de empoderamento das mulheres, em um verdadeiro processo de educação ambiental.

Embora tal perspectiva se apresente como instrumento que parece adequado à construção da arquitetura do empoderamento sustentável, a postura essencialista de que se reveste tal perspectiva ignora os diversos contextos e as relações de gênero que diferenciam homens e mulheres, nos processos de produção e reprodução, além de não permitir integração dessas relaçôes na análise da mudança ambiental.

É importante considerar que as percepções ambientais, que são socialmente construídas, podem sofrer variações no interior da unidade e grupo doméstico, o que pode se refletir nas diferenças de gênero no controle sobre os recursos (VELÁSQUEZ, 2003).

Com base nesses argumentos e objetivando retomar as diferentes perspectivas que orientam a dimensão do Desenvolvimento sustentável e as contribuiçóes dos movimentos ambientalistas, surge, na década de 90, a terceira perspectiva, designada Gênero, Meio Ambiente e Desenvolvimento Sustentável, com os seguintes enfoques: o ambientalismo feminista, a ecologia politica feminista e a microeconomia politica.

$\mathrm{O}$ ambientalismo feminista tem como eixo a relação das pessoas com o meio ambiente que está estruturada por diversos fatores_ gênero, raça_ associados à produção, a reprodução e a distribuição.

A ecologia política feminista, por seu turno, busca a compreensão da forma pela qual se geram e se desenvolvem diferentes interesses sobre o meio ambiente (ROCHELAU, 1995, apud HERNANDEZ, 2010).

Já a microeconomia política do uso dos recursos, destina-se à examinar de que modo as instituiçóes determinam o acesso de mulheres e homens aos recursos naturais e o poder de negociação sobre os benefícios oriundos desses recursos. 
A bem da verdade, a perspectiva Gênero, Ambiente e Desenvolvimento, que mescla aspectos das duas correntes anteriores, relaciona-se com a integração da perspectiva de Gênero no desenho e da instrumentação das políticas e programas do desenvolvimento e ambientalistas (VELÁSQUEZ, 2003).Com isso, realça a importância e a existência de poder nas relaçóes sociais, levando em conta os aspectos de gênero, etnia, classe, raça e geração, além do vínculo com as formas diferenciadas de acesso, uso, controle e conhecimento sobre os recursos naturais. Nessa linha, o poder e o conhecimento são hábeis a fatores mediadores de processo ecológicos e políticos.

Três temas são imprescindíveis para a construção de propostas alternativas sobre o desenvolvimento sustentável, a saber, a divisão de trabalho e de conhecimento por gênero nas atividades cotidianas; os direitos de propriedade e os direitos e responsabilidades da problemática do meio ambiente e análise de gênero nas políticas ambientais.

Dentre esses temas, o relacionado aos direitos de propriedade e à posse da terra têm importante ímpar, uma vez que são fatores mediadores nas relação de gênero e determinam o acesso e grau de manejo dos recursos.

Neste sentido, nos dizeres de Carmen Osorio Hernández (p.27, 2010):

No contexto da América Latina, por exemplo, a mulher rural tem menos probabilidade de possuir terras do que o homem. Esta desigualdade de gênero na posse da terra é atribuída à família, à comunidade, ao Estado e ao mercado. O principal modo pelo qual a posse da terra pode ser adquirida é por herança, na qual a maior preferência é dada para os homens (Deere \& Leon, 2002). Portanto, um elemento importante é entender o papel, a lógica das instituiçôes e dos mecanismos pelos quais os direitos de propriedade e, os processos de tomada de decisão que produzem a divisão de gênero e as responsabilidades, são determinados.

Não se pode olvidar que a noção de desenvolvimento sustentável é relativa e produto de um processo histórico de construção social, que implica mudanças profundas, com o surgimento de novas figuras sociais que apresentam relaçóes de poder e interesses diversos (RAYNAUT, 2004, p 31, apud HERNANDEZ, 2010).

Nesse contexto, o enfoque de gênero mostra sua importância na medida em que insere como atitudes nucleares a vivência e incorporação de açóes de homens e mulheres nas políticas e programas ambientais, e a construção de tais políticas deverá transcender a igualdade de direitos e tomada de decisóes, de sorte a contribuir para uma maior abertura e sensibilidade dos diferentes atores sociais_ instituições estatais, organismos não governamentais e instituiçóes acadêmicas_ no desenho de uma arquitetura inclusiva, a demandar, certamente, método de pesquisa com abordagem multidisciplinar, onde a mediação transformativa encontra espaço como estratégia para pacificação dos conflitos 
socioambientais e alcance do desenvolvimento sustentável intergeracional por meio da prática de diálogos de saberes.

A interação Gênero-ambiente nos programas de ação que envolvem as questôes ambientais, deve levar em conta a vinculação entre os ecossistemas e a população, considerando-se os diferentes elementos da estrutura social que determinam a relação com o meio ambiente além do contexto espaço-temporal e à interação de processos globais e locais.

\section{Inserção na Agenda Internacional e nos Compromissos Internacionais}

Com a finalidade de demonstrar a importância da incorporação da mulher no contexto do desenvolvimento sustentável, faz-se necessário, primeiramente, traçar, no cenário internacional, como o tema se desenhou, na perspectiva da equidade intergeracional.

De fato, o desenvolvimento sustentável depende de um comprometimento com a equidade com as geraçóes futuras, segundo explicita Edith Brown Weis.

Desde a Segunda Guerra Mundial, os Estados têm expressado a preocupação com o bem-estar das futuras gerações. A carta das naçóes unidas afirmou tal preocupação em seu parágrafo inicial: “[...] Nos povos das Naçóes Unidas, determinados a salvar cada geração do flagelo da guerra”.

A preocupação com a justiça para geraçóes seguintes em relação ao meio ambiente surgiu, pela primeira vez, nas reunióes de preparação para a Conferência de Estocolmo sobre Ambiente Urbano de 1972, que trouxe como pilares o Pacto Intergeracional e a Cooperação Internacional. O preâmbulo da Declaração de Estocolmo sobre Ambiente Urbano refere-se expressamente ao objetivo de proteger o bem-estar das futuras geraçóes, para "defender e melhoras o meio ambiente para a humanidade". Tal objetivo deve ser perseguido junto e em harmonia com os objetivos estabelecidos e fundamentais da paz, desenvolvimento econômico e social mundial. A preocupação com as geraçôes futuras e com a melhoria do meio ambiente contribuíram com o processo do desenvolvimento do direito internacional nesse âmbito.

Nessa linha, encontramos o conceito de proteção do ambiente natural para as geraçôes futuras, consubstanciado nas convençóes de Londres sobre Despejo nos Oceanos, em 1972, a Convenção sobre o Comércio Internacional de Espécies em Extinção, em 1973, e a Convenção sobre Proteção da Herança Cultural e Natural Mundial, em 1972.

A Carta Mundial em favor da Natureza, de 1982, demonstra, por outro lado, a preocupação global com a herança que deixamos para as geraçóes futuras.

Como forma de refletir os efeitos de nossas açóes hoje no meio ambiente das geraçóes futuras e de tentar responder à pergunta sobre quando limitar as atividades que representam risco de prejudicar o meio ambiente no futuro desenvolveu-se o princípio da 
precaução no direito internacional, reconhecido pela primeira vez na conferência Internacional do Mar do Norte, em 1987, e invocado durante as negociaçóes para a Convenção sobre Mudança Climática.

\subsection{A Integração das Mulheres e o Desenvolvimento Sustentável}

A integraçáo das mulheres no contexto do desenvolvimento sustentável deu-se nos anos 1970, relacionando-a com as condiçóes das necessidades básicas, a produtividade rural e as atividades no setor informal com ênfase no papel econômico da mulher no processo de desenvolvimento.

Alinhado a essa perspectiva, surge o enfoque teórico denominado Mulheres em Desenvolvimento (MED), já descrito no capítulo anterior e que tem por base as necessidades de maiores oportunidades para a mulher na educação e capacitação, que facilitam o acesso ao setor moderno da economia e ao desenvolvimento econômico.

Pelas críticas tecidas a seu respeito, dentre as quais a de que essa postura enfoca as mulheres sem considerar a situação feminina como produto das relaçóes sociais entre os gêneros, na década de 90 surge a perspectiva de Gênero em Desenvolvimento (GED), que parte da premissa de que as mulheres têm sido excluídas do processo de desenvolvimento. Dessa forma, a incorporação das mulheres na arquitetura de políticas públicas como meio de se alcançar a igualdade legal, política e social, contribuiria para a igualdade na relação entre gêneros e seu empoderamento.

Com essa perspectiva, diversos encontros internacionais são realizados, entre os quais a Quarta Conferência Mundial de Beijing, em 1995, que tem constituído parte do discurso dominante das agências internacionais e instituiçôes governamentais (HERNANDEZ, 2010).

Com efeito, nesta conferência, considerada um marco para a garantia dos direitos das mulheres, em razão dos avanços conceituais e programáticos que propiciou (ARAÚJO apud JUBILUT, 2013), foram aprovadas a declaração e a plataforma de ação de Beijing/Pequim, a partir da avaliação dos avanços obtidos desde as conferências anteriores (Cidade do México, 1975; Copenhague, 1980, e Nairobi, 1985), visando promover a igualdade, o desenvolvimento e a paz para todas as mulheres do mundo, para tanto estabelecendo as condiçóes e os mecanismos institucionais para o desenvolvimento da mulher na sociedade. Outrossim, a assunção do compromisso de realização de tarefas voltadas ao reconhecimento e apoio à participação das mulheres na gestão dos recursos naturais e proteção do meio ambiente por meio de sua ação na tomada de decisóes, tem destacado aspecto na citada Conferência, que ainda se propóe a integração, da perspectiva de gênero nas políticas e avaliações de programas do Desenvolvimento Sustentável (GARCIA \& ABRAMOVAY, 1997; RICO, 1998) 
De acordo com a Divisão da ONU para Mulheres em sua revisão das quatro conferências Mundiais, a transformação fundamental em Beijing/Pequim foi "a reafirmação de que os direitos das mulheres são direitos humanos e que a igualdade de gênero era uma questão de interesse universal, beneficiando a todos" (ARAÚJO apud JUBILUT, 2013).

Em razão da ausência de efetividade dos direitos das mulheres previstos em documentos internacionais anteriores, houve a inclusão, na Declaração do milênio de 2000, de dois objetivos, entre os oito Objetivos do Milênio a serem alcançados até 2015, voltados à concretização de direitos da mulher: 1)Promover a igualdade de gênero e a autonomia da mulher (objetivo 3); e 2) melhorar as condiçōes de saúde das mães (objetivo 5).

Em que pese a existência de tal previsão, Relatório dos Objetivos do Milênio publicado pela ONU declara ainda não ter sido alcançado o Objetivo 3, sobre a igualdade de gênero, destacando que seu cumprimento depende da autonomia das mulheres e da igualdade de acesso por elas à educação, ao trabalho, à saúde e aos processos políticos de decisão política.

A criação da ONU mulheres, em 2010, nessa perspectiva vem corroborar a concretização do direito à igualdade de gênero, defendendo a participação equitativa das mulheres em todos os aspectos da vida: 1)aumentar a liderança e a participação das mulheres; 2) eliminar a violência contra as mulheres e as meninas; 3) engajar as mulheres em todos os aspectos dos processos de paz e segurança; 4) aprimorar a autonomia econômica das mulheres; e 5) colocar a igualdade de gênero no centro do planejamento e dos orçamentos de desenvolvimento nacional.

O relatório de Brundtland trouxe importante contribuição para a inserção das mulheres no contexto do desenvolvimento sustentável, no que toca aos movimento feministas, a despeito de apenas destacar o seu papel nos temas de população e segurança alimentar e não apresentar conclusóes sobre a relação gênero-meio ambiente. É importante realçar que nos idos de 1980 o desenvolvimento apresenta-se com novo significado. De uma visão estritamente econômica, passa a ter como marcos a justiça social, a cooperação internacional e a participação ativa, que, por sua vez, envolve os direitos políticos que traduzem empoderamento.

A participação das mulheres no discurso do Desenvolvimento Sustentável foi, na verdade, colocada pela primeira vez na Convenção da Diversidade Biológica e a Declaração sobre o Meio Ambiente e Desenvolvimento, havida em 1992.

Nessa perspectiva e contexto, a Agenda 21 se afigura de importância ímpar, uma vez que descreve prioridades de ação para alcançar um desenvolvimento sustentável para o próximo século. É no princípio 20 da Declaração do Rio 92 que se materializa esse ideário com a afirmação de que as mulheres têm um papel importante no manejo ambiental 
e desenvolvimento. Disso resulta constituir sua participação fator imprescindível para alcançar um desenvolvimento sustentável.

A declaração referenciada aponta para a justiça social e erradicação da pobreza, que só com nova arquitetura de papéis dos atores pode ser bem enfrentada. A necessidade de implementação de políticas, programas e projetos voltados ao Gênero para a questão ambiental, também é destacada na Agenda 21.

Segundo Carmen O. Hernández (2010), apesar desse reconhecimento, a Agenda 21 apresenta obstáculos limitadores de sua implementação, implicando uma aparente impossibilidade de adequação das mulheres na temática de desenvolvimento sustentável. À guisa de exemplos, a falta de clareza na proposta para um desenvolvimento sustentável, além da falta de decisão política para o estabelecimento de açóes concretas no incremento dos recursos que permitam alcançar um desenvolvimento sustentável e o fato de caracterizar as mulheres apenas como administradoras domésticas da crise ambiental.

No entanto, é necessária uma análise da forma pela qual se pretende entender as relaçóes que existem entre gênero e meio ambiente. Nesse sentido, as mulheres foram inicialmente identificadas como usuárias dos recursos e suas principais depredadoras. A crise do petróleo, em 1973, contribuiu para fomentar tal ideia, uma vez evidenciado que os recursos naturais poderiam perecer.

Já na década de 80, com a intensa participação das mulheres nos movimentos ambientalistas, elas passaram a ser enxergadas como vítimas da degradação ambiental e do processo de desenvolvimento econômico e, simultaneamente, como portadoras do conhecimento sobre a natureza, o que, por seu turno, sujeitaria sua percepção e a tomada de decisôes para a solução destes problemas (AGARWAL, 1991, apud HERNANDEZ, 2010).

A Organização das Naçóes Unidas, na década de 90, incorporou as mulheres como administradoras privilegiadas do meio ambiente, passando a serem tidas como eficientes educadoras ambientais. A partir deste reconhecimento, institutos internacionais, como a $\mathrm{BM}$ e a FAO, estabelecem programas em que se realça o papel das mulheres na biodiversidade e segurança alimentar.

Com esse viés, a Organização Internacional "Woman, Environment and Development" (WEDO), criada em 1990, por ativistas e lideranças de vários países, especialmente do terceiro mundo, reconhece a mulher na sua relação com o meio ambiente como principal usuária e administradora de seus recursos, como protetora dos recursos genéticos e responsável pela alimentação no mundo, por exemplo.

Tal organização tem por escopo transformar o planeta num lugar saudável e pacífico, com justiça social, política, economia e ambiente por meio do "empowerment" das mulheres 
em toda a sua diversidade e pela participação equitativa com os homens em todos os espaços de decisão, com destaque para a seara internacional ambiental, de onde se pode visualizar sua importância para a criação de câmaras para mediação.

Nesse passo, é importante entrelaçar-se os objetivos da referida organização (WEDO) com uma das propostas da Agenda 21, no caso, a implementação de medidas para fortalecer e estimular as instituiçóes e organismos não governamentais e grupos de mulheres para sua capacitação no uso e manejo dos recursos.

Transportando-se essa proposta para a necessidade de se estabelecer um pacto intergeracional para a preservação do desenvolvimento sustentável e levando em conta a dificuldade desse ideário ser concretizado pelos Estados, pode-se afirmar que a Governança Global é ferramenta hábil a tanto.

Mais precisamente, a governança está ligada à arquitetura de um sistema, onde a elaboração de novos arranjos institucionais e organizativos têm importância ímpar na construção da sustentabilidade ambiental. Nesse contexto, a Organização Mundial do Meio Ambiente representa avanço na governança ambiental global.

A governança surge como elemento fundamental no século 21, como única forma de promover o "ciclo virtuoso da sustentabilidade" (GONÇALVES, 2014). Engrandecese a governança, nas questóes ambientais, porque implica na participação ampliada nos processo de diagnóstico, discussão e tomada de decisôes, encontrando na mediação terreno fértil, porque garante legitimidade aos autores.

O direito, assim, passaria a ser concebido como uma grande plataforma onde todos os atores se encontram para a busca de um resultado finalístico de gestão ambiental com nova feição, onde a figura dos órgãos de tratados têm papel preponderante nos acordos ambientais multilaterais. Com efeito, passam eles a serem enxergados como uma nova forma de cooperação internacional, mais eficientes e flexíveis do que as organizaçôes internacionais tradicionais.

Os órgãos de tratado, segundo Kiss e Shelton (apud BEYERLIN e MARAUHN, 2004) atuam com capacidade quase legislativa na tomada de decisóes, além de manter a flexibilidade e capacidade de responsabilidade internacional ambiental dos tratados, tendo importância marcante na eficácia de acordos, que podem ser gestacionados pela mediação ambiental.

Nesse contexto, as COPS (Conferências ou reuniôes das partes), têm apresentado relevante contribuição para o desenvolvimento da governança ambiental internacional à semelhança de um etos planetário, que, conduzida por mulheres, em relação da sua reconhecida habilidade de assegurar a paz intergeracional, por razóes culturais e sociais, implicaria em verdadeiro "empowerment" na condução dos conflitos socioambientais internacionais. 
Parafraseando Edith Brown Weiss (1992), precisamos de um etos que seja planetário na abrangência e incorpore todas as geraçôes. Isso requer que nós aumentemos a consciência pública e eduquemos as pessoas por meio da mediação, sobre o desenvolvimento sustentável.

A paz e a cooperação intergeracional, então caminhariam juntas na agenda ambiental internacional do desenvolvimento sustentável, constituindo forte resposta à resistência à adoção de novos instrumentos internacionais.

\section{Conclusões}

1. A utilização da mediação transformativa, enquanto um dos meios alternativos de resolução pacífica de conflitos, é ferramenta hábil na gestão dos conflitos socioambientais;

2. As mulheres têm papel essencial no desenvolvimento sustentável, oferecendo contribuição na conservação da biodiversidade ao dar ênfase à cultura local, à valorização do conhecimento popular sobre o uso e manejo de recursos, além do estímulo à participação no resgate e aumento da biodiversidade.

3. O enfoque de gênero mostra sua importância na medida em que compreende, como atitudes nucleares, a vivência e a incorporação de açóes de homens e mulheres nas políticas e programas ambientais.

4. A construção de tais políticas deverá promover a igualdade de direitos e tomada de decisôes, de modo a contribuir para uma maior abertura e sensibilidade dos diferentes atores sociais no desenho de uma arquitetura inclusiva, a exigir métodos de pesquisa com feição multidisciplinar, onde a mediação transformativa tem lugar importante como estratégia para pacificação dos conflitos socioambientais e alcance do desenvolvimento sustentável intergeracional, por meio da prática de diálogo de saberes;

5. O empoderamento da mulher se assemelha a um etos que seja planetário no recorte intergeracional, o que demanda consciência e educaçáo das pessoas na perspectiva do desenvolvimento sustentável, pela prática da mediação transformativa.

\section{Referências}

ANRIQUEZ, Gustavo; BOJANIC, Alan. Mulheres na agricultura: brechas de desenvolvimento. Disponível em <https://www.fao.org.br/vernoticias.asp?id_noticia $=1000>$ Data de acesso: 26.11.14.

BEDÊ, Judith Aparecida de Souza; FERENC, Lissa Cristina Pimentel Nazareth; e RUIZ, Ivan Aparecido. Estudos preliminares sobre mediação. Revista Jurídica: CESUMAR. v. 8, n. 1, p. 163-177, 2008. Disponível a partir do site <http://www.cesu- 
mar.br/pesquisa/periodicos/ index.php/revjuridica/article/view/727/563>. Acessado em 15 de ago. de 2013.

BEYERLIN, Ulrich; MARAUHN, Thilo. International Environmental Law. Oxford: Hart Publishing, 2011.

BRITO, Maria Cecília Wey de. Líderes e celebridades internacionais defendem mais açóes globais contra mudanças do clima. Globo News: Jornal das dez. Disponível em: <http://globotv.globo.com/globo-news/jornal-das-dez/v/lideres-e-celebridades-internacionais-defendem-mais-acoes-globais-contra-mudancas-do-clima/3649864/> Data de acesso: 26.11.14.

BUSH, Robert A. Baruch; FOLGER, Joseph P. La promessa de Mediación: cómo afrontar el conflicto a través del fortalecimento propio y el reconocimiento de los otros. $1^{\mathrm{a}}$ ed. Buenos Aires: Granica, 2010.

CARDOSO, Simone Alves et al. A mediação como estratégia utilizada pela magistratura na gestão sustentável dos conflitos socioambientais. In: iii congresso de internacional de direito ambiental internacional da universidade católica de santos, 3., 2014, Santos. Anais. Santos: Editora Universitária Leoopoldianum, 2014. v. 1, p. 7 - 284.

ERNANDORENA, Paulo Renato. Resoluçóes de Conflitos ambientais no Brasil: do patriarcal ao fraternal. Estudios Sociales. v. 20, n. 40. México, 2012. Disponível a partir do site <http:// www.scielo.org.mx/scielo.php?script=sci_arttext\&pi$\mathrm{d}=$ S0188-45572012000200001\&lng=es \&nrm=iso $>$. Acessado em 10 de abr. de 2014.

FERREIRA, Fernando Martins. A mediaçáo como exercício de cidadania na soluçáo dos conflitos socioambientais: o caso dos produtores rurais situados às margens da microbacia hidrográfica do arroio lajeado da cruz. Apresentada como dissertação de mestrado em Direito, Universidade Regional Integrada do Alto Uruguai e das Missóes - URI. 202 p. Santo Ângelo, 2010. Disponível a partir do site <http:// www.urisan.tche.br/mestradodireito/pdf/2010/ Fernando_Martins_Ferreira.pdf >. Acesso em 18 de mar. de 2014.

FILHO, Jaime E de Oliveira. Gestão ambiental e sustentabilidade: um novo paradigma eco-econômico para as organizaçóes modernas. Domus on line: Ver. Teor. Pol., soc. v. 1, n. 1, p. 92-113, 2004. Disponível a partir do site <http://www.fbb.br/media/ Publica\%C3\% A7\%C3\%B5es/Domus\%20N\%C2\%BA1\%202004/domus_jaime. pdf>. Acesso em 04 abr. de 2014.

HERNANDÉZ, Carmen Osório. Gênero e Meio Ambiente:: a construção do discurso para o desenvolvimento sustentável. Ambiente y Desarrollo:: genero, agroindustria y ecología, Bogotá, v. , n. 26, p.1-127, jun. 2010. Título Original: Género y 
medio ambiente: la construcción del discurso para el desarrollo sustentable. Disponível em: <http://revistas.javeriana.edu.co/index.php/ambienteydesarrollo/article/ view/1092>. Acesso em: 26 nov. 2014.

JUBILUT, Liliana Lyra et al (coords). Direito à diferença:: aspectos de proteção específica às minorias e aos grupos vulneráveis. São Paulo: Saraiva, 2013.

JUNIOR, Sidney Rosa da Silva. A mediaçáo e o interesse público ambiental. Revista eletrônica de direito processual: periódico semestral da pós-graduação stricto sensu em direito processual da UERJ. Ano 3. Volume III. 284 p. Rio de Janeiro, 2009. Disponível a partir do site <http://redp.com.br>. Acesso em 26 de abr. de 2014.

KABEER, Naila. Realidades trastocadas, las jerarquías de gênero en el pensamiento del desarrollo. México: Paidós/unam, 1998.

MOREIRA, Roberta P. Mediação de conflitos no âmbito da defensoria pública. Monografia para obtenção do título de Especialista em Direito Público, Escola Superior de Magistratura do Estado do Ceará - ESMEC. 50 p. Fortaleza, 2013. Disponível a partir do site <http://bdjur.tjce.jus.br/jspui/bitstream/123456789/617/1/ Mono\%20Esmec\%20Fatima.pdf>. Acessado em 02 de dez. de 2013.

SARLET, Ingo Wolfgang. A eficácia dos Direitos Fundamentais:: uma teoria geral dos Direitos Fundamentais na perspectiva constitucional. 10. ed. Porto Alegre: Livraria do Advogado, 2009.

SILVA, Aurélia Carla Queiroga da et al. A mediaçáo como mecanismo de resoluçáo de conflitos socioambientais. Ciência e internalização: os desafios da pesquisa na UERN. VII Salão de Iniciação Cientifica da Universidade do Estado do Rio Grande do Norte do Rio Grande do Norte. Rio Grande do Norte, 2010. Disponível em <http://www.uern.br/sic/sic2010/ arquivos/VI_SIC.pdf >. Acessado em 12 de abr. de 2014.

SOARES, Samira I. de Oliveira. A mediação de conflitos na gestáo de recursos hídricos no Brasil. Apresentada como Tese de Mestrado em Ciência Ambiental, Universidade de São Paulo - USP. 172 p. São Paulo, 2008. Disponível a partir do site <http:// www.iee.usp.br/biblioteca/producao/2008/Teses/SamiraIasbeck.pdf $>$. Acessado em 10 dez. de 2013.

SOUZA, Luciane Moessa. Meios consensuais de soluçáo de conflitos envolvendo entes públicos: negociação, mediação e conciliação na esfera administrativa e judicial, Belo Horizonte: Fórum, 2012.

TORRES, Claudia Vechi. A mediaçáo como mecanismo de resoluçáo de conflitos socioambientais. Monografia do Curso de Especialização em Desenvolvimento Sustentável e Direito Ambiental, Universidade de Brasília. Brasília, 2010. Disponível a 
partir do site < http://bdm.bce.unb.br/handle/10483/149>. Acessado em 08 de abr. de 2014.

WARAT, Luis Alberto. O ofício do mediador. Florianópolis: Habitus, 2001.

WEISS, Edith Brown. Environmental change and international law: new challenges and dimensions. Tokyo: United Nations University Press, 1992. 55 p.

GARCIA, M. \& Abramovay, M. Gênero e Meio ambiente. São Paulo: Cortez Editora. 1997.

Martínez, B. Género, sustentabilidad y empoderamiento en proyectos ecoturísticos de mujeres indígenas. Revista de Estudios de Género. La ventana, 17, 188-217. 2003.

Rico, N. (1998). Género, medio ambiente y sustentabilidad del desarrollo (Documento técnico No. 25, serie Mujer y Desarrollo). Santiago de Chile: Comisión Económica para América Latina y El Caribe (CEPAL).

Velásquez, M. Hacia la construcción de la sustentabilidad social: ambiente relaciones de género y unidades domésticas. En E. Tunón (Coord.), Género y Medio Ambiente. México: Plaza y Valdés. 2003. 